\title{
The Legitimacy of Power and Power relations as a Multi-level Political and Legal Phenomenon: Approaches, Interpretation and Conceptualization
}

\author{
Pavel P. Baranov ${ }^{1}$ \\ Aleksey Y. Mamychev² \\ Aleksey I. Ovchinnikov',3 \\ ${ }^{1}$ South-Russian Institute of Management of the Russian Academy of National Economy and Public Administration under the \\ President of the Russian Federation \\ 2 Vladivostok State University of Economics and Service \\ ${ }^{3}$ Rostov Law Institute of the Russian Ministry of Internal Affairs; Email: mamychev@yandex.ru
}

\author{
Doi:10.5901/mjss.2015.v6n5s3p209
}

\begin{abstract}
The article analyzes the legitimacy as a complex, many-sided and multi-level education, argues that the legitimation of power is carried out at different levels, and the process of legitimation involves both individuals and various groups and organizations. It is noted that the legitimacy is represented as a goal of the functioning of all institutions of public authority and as a result, which is meaningfully concretized with a series of interrelated phenomena (legitimization, legitimate regime and etc.). In its turn, the concept of "legitimacy" is interpreted by the authors as the estimated characteristics, applying to either specific political actors and their actions (personified legitimacy), or to existing institutions and public-authoritative activity (institutional, impersonal). The article also introduces the author's approach to the allocation of interconnected levels of legitimacy: 1) the types of internal (motivational) and external (institutional) legitimacy; 2) the types of legitimate domination defining the dominant strategies of substantiation of existing institutions and the ways of social processes managing; 3) the regimes of the legitimation; 4) the forms of substantiation of a state power as such, and its inherent institutional and legal structure.
\end{abstract}

Keywords: power, authority, power relations, institutions, legality.

\section{Introduction}

Traditionally, power, power relations in society, including ways of legitimation of this power and its activities, are described and analyzed by structural-functional approach. Structural power relations and the mechanism of power legitimization very often coincide and are reduced, as a rule, to three interrelated elements: subject, object and content. This structural model of power relations represents the idealized theoretical structure having a number of weak spots in the description and analysis of the actual public-authoritative interactions unfolding in the society.

For example, the most common definition of power within the subject-object model in social science is the following: it is a relationship of domination and subordination in which the will and the actions of some individuals (powerholding subjects) dominate the will and the actions of others (subordinates). The problem seems to be clear. However, even a perfunctory analysis of the existing practices of authorities call into question the previous statement, the logic of the analysis of power relation itself.

Of course, one can agree with the above-stated structural and functional model of legitimation, however, this structural model of legitimacy phenomenon essence describing is a narrow approach, not taking into account the complex and ambiguous process of authoritative and legal organization development and its legitimation in different historical and cultural contexts. Let's state a few thoughts on the subject.

First, this model works with the already existing, stable configuration of institutions and power structures, interpret the processes of legitimation in the context of a certain historical stage of development and practically is not admissible for the description of the transition and crisis conditions of power-political interaction. It does not capture the processes of legitimation of power in the context of replacement, revolutionary breaking or the transformation of institutional power structures.

Second, the thesis that "only the people is a singular subject of power legitimation" and "Power-holding subject should really be aware of its right to the power (potential legitimacy)" refers more to proper than to existed one. It seems 
that the process of the legitimate evolution of the state power is more diverse and complex, it is based not only on the individual (subjective) positions and actions, but also depends on the inter-subjective factors of political life (the current style of political thinking, the models and forms of the authoritative interaction, which in many respects are successively reproduced from generation to generation).

Third, it does not take into account that in some cases the functioning of specific institutions and officials may, in fact, fit in with the existing principles and forms of institutional authoritative organization, but contradict the national expectation, social outlook, and so on. Even the official terminology used in state-building and political rhetoric can undergo public "repression", significantly reducing the level of legitimacy of the entire authoritative-legal organization.

Fourth, with all the evidence and simplicity of the subject-object model the question of who is currently the subject and who or what is the object of legitimation always remains open, as long as any activity, any person caught in the area of political reflection, initiates the process of legitimation (delegitimization). In other words, the subject and the object of legitimation and their interaction are determined in each case again, with reference to the context and the situation (contextuality).

In this paper, legitimacy is seen as a complex, many-sided and multi-level phenomenon. In this respect it is argued that the legitimation of power is carried out at various levels, the process of legitimation involves both individuals and various groups and organizations. Moreover, legitimacy may apply to specific representatives (personified legitimation), to specific institutions (impersonal legitimation) and to the entire institutional and power order, the entire political sphere of society.

\section{Literature Review}

In the current research strategy one try to get away from the traditional structural scheme of the analysis of power relations (Clemens E.S. and Cook J.M., 1999; Hall P.A. and Taylor R., 1996; Lira J., 1988; Landort P. and Goldring L., 2010; Lounsbury M. and Glynn M.A., 2001 and March J.G. and Olsen J.P., 1984 et al.). Today, the emphasis is shifting towards the analysis of not the subjects themselves, their classification and typology, but the national and cultural conditions and typed practices that determine authoritative thinking and action. Typically, while the traditional approach the researcher stands in the position of the objective observer, interpreting and describing the subject as a particle (element) of the structure, abstracting it from the social and political action and depriving of the cognitive activity and the role of random variation in its activity, and the cultural "background" impact in level of general analysis.

In its turn, in the center of current research projects there is the analysis of the conditions and specific practices of thoughts and actions that in this or that different social spheres generate the subjects of powerful interaction, the specific forms of domination of one over the other subjects, the methods and techniques of specific power positions substantiation, the reconstruction of types of political reflection that supports a certain system of knowledge, political axioms, truths, theoretical propositions and postulates that are the foundation for understanding and the legitimation of power, the institutional order as a whole (P. Bourdieu, 1993 and M. Foucault, 1996, etc.).

It raises the question of how a whole of knowledge, traditions, values, norms, forms the social and power positions in this or that public domain (legal, economic, political, religious, etc.), i.e., everything is analyzed that makes the functioning of the authorities justified, but independent of the specific subject.

As part of the Humanitarian Research there is a number of authoritative approaches to the analysis of legitimacy, as a complex, multi-level and structural phenomenon. For example, a well-known political scientist D. Easton singled out the following structural types of legitimacy: 1) personalized - the legitimization of the specific statesmen by the citizens; 2) structural - the legitimation of state and other political institutions and structures, functioning in the society; and 3) ideological - the legitimization of the whole state and legal system, based on a certain system of norms and values (Easton D., 1960). As one can see, D. Easton offers not only the classification of types of legitimacy, but also emphasizes its multi-level structure.

A similar multi-level structure of the legitimacy is represented by a modern political scientist A.-N.Z. Dibirov (Dibirov A.-N.Z., 2007). So, based on the "voluminosity" of the state power legitimization he highlights: a) the first level - the legitimization of state power as such, as a national-cultural and socio-historical foundation of all processes of legitimation; b) the second level, or floor of legitimacy which is built on the existing foundation - the legitimation of a specific form of political life, which support institutions and procedures existing in a society; c) the third (floor) level - a legitimization of specific politicians, their activities and ways of "entering into power".

A fundamentally different architectonics of legitimacy was offered by sociologists of knowledge P. Berger and T. Luckmann. They singled out four levels of legitimacy, not based on the "volume" of legitimation of political space and political actors and institutions acting in it, but on the levels of social knowledge (Berger P.L. and Luckmann T., 1966). So, 
they point out: 1) pre-theoretical level, the content of which includes the "self-evident knowledge", represented by the tradition which, in accordance with it, is the foundation for all subsequent levels of legitimation; 2) the second level is the first theoretical generalizations ("theoretical statements in its initial form"). They formulate ordinary, pragmatic schemes (typifications), representing the collective political experience in public-authoritative interaction in its compressed version, "folk wisdom", etc.; 3) the theoretical level represents already formulated theories with which the institutional order is legitimized; 4) the fourth level of legitimation - symbolic universia, including the "systems of theoretical tradition, absorbed various fields of knowledge" and "institutional order in all its symbolic integrity".

In the context of this study, these theoretical and methodological developments are summarized and different, more appropriate, in our view, architectonic (multi-level structure) of the legitimacy of power and power relations is formulated.

\section{Methods and Materials}

The authors in their paper base on the of the following methodological grounds: first, the legitimacy is regarded as a qualitative state of the political and legal organization of society; second, legitimation is analyzed as the process of this condition achieving; third, the first and the second grounds have no universal and strict univalent structure. However, the authors believe that in the theoretical and methodological context one can distinguish different levels, cuts of legitimation. From this perspective, one should speak about the architectonics of legitimacy, i.e. about interconnected layers (levels) of national and cultural legitimation of power and political order.

In the theoretical-methodological and practical terms, this study is based on the provisions of the new institutionalism, developed in the works of authors such as P.G. DiMaggio, J.. March, J. Norton, G. Olson, R. Taylor, J. Wallace O. Favereau, P. Hull, F. Aymar Duvernet et al in which political institutions are interpreted widely enough, on the one hand, as formal rules, regulatory models, procedures and standards; and on the other as symbolic systems, cognitive scripts, socio-cultural and spiritual-moral patterns, which organize and manage the mental activity of people. This approach is most relevant for adequate description of the legitimacy of power and power relations as the institutional and regulatory and socio-cultural phenomena.

\section{Results and Discussion}

In modern approaches a multi-level structure of the legitimacy is based on either the extent of legitimacy processes coverage, or a "depth" of a theoretical substantiation of the institutional order. In the first case the emphasis is on institutionalized subjects of power, their personalized and depersonalized legitimation, in the second - in the everyday and the theoretical tradition of justification of not so much the subjects of power as existing institutional order. At the same time, we believe that the legitimacy, in addition to the characteristics given above, should also include behavioral aspect, i.e., the types of legitimation of power relations in the daily practice of political cooperation, and in addition to types of legitimate domination, specific regimes of legitimation of government institutions and their functioning, eventually forming some form of substantiation of the government and political order.

Taking the given above into account, four interrelated levels should be divided: 1) the types of internal (motivational) and external (institutional) legitimacy; 2) the types of legitimate domination defining the dominant strategy of substantiation of existing institutions and ways of social processes managing; 3 ) the regimes of legitimation, which comprehensively reflects, on the one hand, a system of means, methods and tools for the functioning of government institutions and agencies justification, and on the other - a systemic evaluation of actual public-authoritative relations developing in the process of thinking activity of subjects and their interaction on the implementation of national interest or the common good; 4) forms of substantiation of state power as such, and its inherent institutional and legal structure.

\subsection{The level of internal and external substantiation of the legitimacy of the existing power relations}

In the daily practice of social actors. According to M. Weber, at this level it is possible to distinguish several types of social practices in which a legitimate value is attributed to various phenomena and processes. The allocated types of social action, according to $\mathrm{M}$. Weber, contains not only an internal motivational structure, but also a certain social meaning, which is expressed in the ratio of subjective behavior with the behavior of other people.

In other words, in the context of this action existing, established patterns of behavior in society, the real practice of interaction, as well as possible reactions from others are taken into account. In this regard, public practice, in which the legitimate importance attributed to this or that political phenomena should be classified into four main steps: goal-oriented 
rational, value-rational, affective, traditional (A.F. Filippov, 2002, p. 98).

Traditional action is based on existing traditions, customs, habits, etc. Here legitimacy is attributed to everything that corresponds to the age-old image of order, justice, harmony, and every action is significant in relation to the eternal being. At that this traditional foundations of social interaction are perceived as a spiritual landmark, as an example of genuine and adequate social, legal, political organization of social relations, rather than as a set of ready-made recipes of social action. This type of social practices is usually called passive, due to the fact that the subject of political interaction has no reactions (explicit or latent) over the existing power and legal institutions, due to the fact that their operation fits into the tradition, corresponds to the usual course of things, the primordial image the power of organization and order.

Affective type of social action is based on an emotional belief in the importance of (legitimate) of certain government actions of personalized or impersonal (institutional) nature. The given type reflects the irrational underpinnings of social behavior formed on the basis of a certain psychological state, which is forming under the influence of real-life situation and the world of the unconscious structures. It is obvious that social interaction is realized and rationalized only selectively, with "spots", connects highly rationalized forms of consciousness (legal ideology, politics, etc.) with the world of the unconscious structures, unconscious cultural codes (archetypes), psychological states and trends, determining thereby the attitude of the individual towards politics, law, government and other phenomena of political reality, behavioral, psychological and normative self-actualization of the individual (Alexey I. Ovchinnikov, Alexey Y. Mamychev and Svetlana F. Litvinova, 2015). Therefore, the appeal of research attention to the irrational basis of the process of legitimation is very popular and justified.

Goal-oriented rational type is based on giving legitimacy to the actions and structures that contribute to the achievement of individualized goals. In other words, everything around acquires meaning and significance only through the prism of individual, private good. The category of "efficiency" is the main point in the concept of legitimacy, as "all is legitimate, that promotes the effective achievement of the goals and objectives of individual existence." Therefore, in this type of social interaction the legitimacy acquires those institutional ties that could provide a regime of free, attached to nothing (no morality, no tradition, no appeal to the collective ideals, etc.) existence of individuals realizing their utilitarian interests and needs, and create the conditions for an isolated and self-sufficient functioning of various social units.

Value-rational type is based on the fact that the legitimacy is based on the belief in the absolute value of the taken for granted action itself, corresponding to the certain rational value in the regulatory system. In this aspect the institutions, structures and the activity itself that express commonly shared system of basic values and norms that lead to their daily implementation possess social value. It is exactly due to these axiological grounds of social interaction the institutionalization of other instrumental (secondary) values, such as government, legal and social institutions is directed and legitimized. It is exactly the secondary characteristics of the latter determines their social purpose and the process of their legitimation. Their goal, their social purpose is realized through the institutional mechanisms of primary, basic social values and needs.

However, if the above-mentioned types of social action guarantee, according to M. Weber, the legitimacy merely internally, i.e. different types of authority justification in daily activities, private life, so it is advisable to isolate and examine the types of external justification of power, power relations in the public sphere. So, from our point of view, one should highlight the social mechanisms of the external organization and justification of power interconnection and power reflection itself. These include political identity, political ideology, spiritual and moral dominants, institutional (political ideology, economic efficiency), discourse types.

Political identity as a type of legitimation is based on historically formulated world outlook directions, reflecting synthesized image (formulated on the interpretation of the past, present and future of the nation) of power, order, justice. It is obvious that social interaction in the political dimension is mediated by collective identity which, strictly speaking, is a form of political subjectivity. In other words, the collective identity is a certain political reality, which determine the formation of specific political subjects of their specific characteristics and also the interaction between them.

Institutional type of legitimacy. At the level of everyday behavior and interaction the legitimization of authority and legal activity of various political actors, the individual government institutions and structures, their authorized representatives is carried out, as well as approbation and "habitization" (typification) of power interaction models in society takes place. Typification of expected authoritative behavior sets specific institutional tradition of accomplishment and comprehension of the power relations; and the "origins of any institutional order are in typification of accomplished actions, both our own and other people's one» (Berger P.L. and Luckmann T., 1966). Thus, a separate institute is conceptualized here as an expression of the "objective" human activity.

The ontological type of legitimization is connected with the adequacy of institutions of public authority to established order, "inscribed in the human and social reality" (J.-L. Chabot). At the same time this institutional order is a continuation of the historically established order of things, corresponding to spiritual and moral reference points of social 
life of people, their daily social practices, etc. Hence, "the level of ontological legitimacy of political power would lie in the level of correspondence to the depth order of being that person feels innately» (Chabot J.- L., 1991, p. 68). The given type of legitimacy is based on the fact that "there is always a set of practices and techniques that escape from the legal systematization and order. That does not mean that this set is "anemic", arbitrary in the true sense, but it is subordinate to relatively different logic than the logic of the legal order", first of all, to the logic of interaction between the individual classes, strata that "is reflected in the laws by itself and to specific measure" (Poulantzas N., 1978, p. 92-93).

In addition, in the context of external justification of existing institutions and their function in the daily practice a specific, patriotic, type of legitimacy is distinguished. This type of legitimacy suggests that the pride of a man for his home country, his government and its internal and external policies are recognized as the highest criterion of support for authorities.

The analyzed inner and outer bases of the adequacy of government institutions, as a rule, in real political reality intertwine and mutually complete each other. For example, the Russian people have a value-rational and conservative style of behavior, ontological and traditional way of thinking. They appreciate not so much important goals and results, as the meaning of transformations, their spiritual and moral, rather than institutional and normative dimension.

\subsection{The types of legitimate domination}

The types of legitimate domination defining the dominant strategy of substantiation of institutions and applying ways of social processes managing. This level of legitimacy is based on internal and external types of legitimation of the government, acting at the level of everyday social and authoritative interaction. Three classic types of domination traditional, charismatic, legally, - distinguished by $\mathrm{M}$. Weber are traditionally referred to the given types.

Traditional legitimacy relies on a complex system of customs and traditions that are played from the time out of mind and supported with a social habit rooted in the human to stick to established social forms and patterns of interaction. In this regard, such institutional structure that the most appropriately embodies the way of old established order of things, represents and supports national identity, holds in its functioning to social and cultural forms and patterns of interaction in the personality - society - state system becomes legitimate.

In the tradition above all on the one hand, the elements that are type-formulating factors of certain social phenomena (the state, law, government, justice, etc.), are revealed and on the other - it contains the mechanisms for monitoring and broadcasting the unique social-legal and ethno-political experiences determining a particular culturecivilizational type of particular society, the state, law.

At the same time the traditional legitimacy must be viewed in two ways, i.e., one distinguish between technical and existential institutional continuity. So, if the first, according to V. Volkov, reflects devotion, obligation to "play the game", the second represents the admitting of a way of life, readiness to become and to be historically conditioned social actors (V.V Volkov, 1998, p. 165-169). And the latter is based on a particular way of political thinking activity, which to a certain extend determines the uniqueness of the legal and political life of the nation at various stages of the political system evolution. Thus, each socio-domineering subject experiences traditional experience and behaves in conservative way, as "he is included in one of the phases of development of this objective mental structure (usually in a contemporary phase for them) and behave in accordance with this structure or simply reproduce it entirety or in part, or develop it further through adaptation to specific life situations" (Manheim K., 1994, p. 596).

The second type of domination is a charismatic legitimacy, characterized by personal devotion of the social and political subjects to the case of some person and their faith only in his personal dignity, in a person that distinguish himself in heroism, exemplary quality, sacred character and other extraordinary features. "In the case of charismatic domination - marks M. Weber, - one submit to a charismatic leader as such due to personal faith in his revelation, valor or exemplary features, that is, his charisma "(M. Weber).

This type of legitimate domination, according to M. Weber, is extremely personalized. Here political subordination, institutional development are determined by personality. Leaderism and elitism are the leading factors determining specificity of the functioning of all spheres of public life. Charismatic legitimation is not directly related with rational judgments and is based on the range of feelings and emotions. It is a sensory legitimation by its nature, although, of course, it has a rational interpretation, but as a secondary phenomenon. In addition, those institutions that contribute to the implementation of a great idea, formulated by the leader or continue the deed started by him will be provided with the "secondary" legitimation.

The third type of legitimate domination is a legal (rational) legitimacy. It is, on the contrary, the ultimate form of impersonal domination, in which socio-political actors are subordinate to impersonal institutions and structures, their officials, on behalf of whose at the present moment on the grounds of legal procedures the society is governed. "In the 
case of a legal domination people obey the lawfully established objective impersonal order (and superiors established by that order) by virtue of the formal legality of its orders and within them" (M. Weber).

Thus, the essence of this type of dominance lies in the government institutions accordance with a rational-legal principle by which the political order is established. In practice, such legitimacy is expressed through adequacy, the compliance of existing political institutions with the requirements of a rationally constructed order enshrined in various regulatory legal acts (primarily in the country's constitution). Consequently, this model of legitimation of state power is based on a rational assessment and related primarily to forming of the conviction of the reasonableness of the existing order, laws, rules.

The rational legitimization implies that the population support (or reject) the state power primarily on the basis of their own assessment of the actions of this government. No slogans and promises (they have a relatively short-term effect), not the image of a wise ruler, often no even fair laws, but practical activities of public authorities and officials, especially high, is the basis of rational evaluation (Chirkin V.E., 1995). Rational legitimacy (or legal legitimacy) in its final form - states J.L. Kermon - is formed nowadays in the declarations and preambles of all existing democratic constitutions and recently such legitimacy is sanctioned by prohibition on the revision of the basic legal texts (Quermonne J.-L., 1986, p. 16).

\subsection{The third level is a regime of legitimation}

The third level is a regime of legitimation of the government, its individual institutions and structures, as well as officials representing them. If considered types of domination, marked by $\mathrm{M}$. Weber, represent the ideal strategies of legitimation and are essentially static (strategic) legitimizing principles, then, in its turn, regimes represent a set of means, methods and tools of the justification of the functioning of government institutions and structures and also reflect the assessment of actual power relations forming in the process of thinking activity of subjects and their interaction on the realization of the common good and national interest. These regimes reflect the "true state of affairs", the actual practice of the authorities and their perception by the public conscience. Integrating the groundwork in this field, the following regimes of the legitimation of power can be distinguished: liberal-democratic, technocratic, ideological, ideational, ideocratic.

Liberal-democratic regime associated with the -legitimization of public-authoritative institutions through the concept of "common good". At the same time, the idea of the justification of political governance is based on the fact that all the activities of institutions are evaluated in terms of realization and provision of that good. Axiomatics of a given regime assumes a qualitatively different reality than a simple collection of individual wills. At the same time, individual perceptions of free judgment are the starting point, a "unit" of legitimation.

In its turn, the principle of "arithmetical majority" is used for the operationalization of the transition from the individual to the collective (public). This principle becomes universal for all liberal democratic regimes; it is associated with both the selection of the legitimate representatives of the people and the forming of legal and political institutions, legitimate decision-making in the context of legitimate collective structures. In this context "the procedures of majority voting - notes J.-L. Chabot - are not "the Mouth of Truth," not a modern form of the ancient oracle, simply because the political sphere is primarily a sphere of conjuncture and game of opinions, not dogmatic revelations" (Chabot J.- L., 1991, p. 61).

Technocratic regime of legitimation is based on the idea of the effectiveness of state (wider - public) administration, the main thesis of which is the consideration of public policy as a specific art ("public management"), which requires specific skills, knowledge and abilities and is carried out by specialized social group.

The degree of legitimacy of the functioning public-legal institutions is conditioned on the level of social interests and needs satisfaction. On this occasion, the process of legitimization in a greater degree depends not on the institutional and regulatory coding of social interaction, but on the contrary on managerial knowledge and skills of the political elite. In this case it is asserted that "a real power - is the rower of knowledge" (Chabot J.- L.), which provides a breakthrough in both a technology and material sphere. It is obvious, that this regime of legitimation combines the versions of economism and elitism. A political and economic expediency (efficiency) are the main legitimizing bases there.

The ideological regime of legitimation is performed by recognition of and trust in the correctness, exclusive of certain ideas of political and legal development, which are proclaimed and implemented by institutions of power. Here the political ideal of social order is postponed into the indefinite future, becomes an energy stimulus for social-legal and administrative reforms of the present. That is a kind of dictatorship of abstract principles and metaphysical bases in its own way. And therefore "the power almost merges with the ideology ... becomes invisible, dissolving in numerous cells of the social organism ... the state as an ideal infinitely expands, it absorbs all the autonomous formations: as an ideology, statehood naturally seeks to totality" (I.A. Isaev, 2003 , p. 497). Hence the statement that political institutions can be 
legitimized more or less in compliance with the ideas about social reality.

Ideational regime of legitimation. The concept of "ideationality" is introduced by Russian sociologist P.A. Sorokin, which he used to denote such authoritative-legal organization, in which a traditionalist type of organization represented the dominant of public-legal institutions functioning; and the vertical of value-normative hierarchy is oriented from the earthly world to the supersensible and its absolute dominant - God. Ideational legitimation is based on ideational ethics, which is characterized by dismissive attitude towards social values, material goods, wealth, and bodily pleasures. Earthy well-being is viewed by it as something secondary. In its turn, the principles of political organization are regarded as the given above, perceived as the absolute requirements, demanding unquestioning execution and avoiding any modifications. In the ideational political and legal system any obedience to existing institutions is equivalent to obedience to God. In it peculiar for ideational political outlook to uncritically trust the power of the existing institutional-authoritative system; it is forbidden to question the legitimacy of its existence.

In its turn, the legitimacy of existing public institutions of authority depends on their compliance with the principles of religious normativity. Public agents in this system are guided by not only legal prescriptions but also spiritual and religious ethics, and political and legal procedures take the form of sacred rituals. Thus, "in the states of ideational orientation only those rulers whose lineage goes back to the Gods, as well as those who have a direct divine mandate to rule possess legitimacy" (Bachinin 2005, p. 105).

Ideocratic regime of legitimation is based on a set of objectively existing historical factors that are interpreted by a system of ideals and ideas. Here, the source and meaning of the state power is in tie with the ideological content of the principle that this nation is taken as the beginning of an absolute ideal, as above-empirical reality. The ethical ideal of the nation is determined by this content as this or that codex of moral requirements; it also determines that idea, that aspect of the genesis of power, which dominates the national public life in the State (P.P. Baranov and A.A. Gorshkolepov, 2002, p. 22).

The legitimacy of the government in this regard specified in the latter serving to the last general idea, which is developed in the course of the inner spiritual state and legal life of society, and exactly due to this general idea following it is on a real altitude; the government existence and position in the society is motivated by serving this altitude. From the viewpoint of N.S. Trubetskoy, the principle of an ideocretic statehood is in the presence of a world view commonness, a special system of beliefs which are shaping the supreme idea of the nation ("idea-regent").

Thus, the political actors enter into power relations when they have been already included in the forms of power interaction at the level of social commonnesses (communities). Therefore, the authorities are perceived not so much as interpersonal relationship of subjects, their groups, but rather as a general socio-cultural form institutionalized in the public institutions.

In this context, integrativity and legitimacy of institutional authoritative organization of a society is provided not by search for a consensus between contradicting multidirectional and various political forces on the basis of consensus in the institutional and regulatory procedures, but rather in the spiritual and moral education of members of the various communities in the context of socio-political service to national unity.

\section{Conclusion}

5.1. The legitimacy is an aim of the functioning of all institutions of public authority and is also a result, which is meaningfully revealed and concretized through a series of interrelated phenomena: a) of legitimization - as a process, methods, techniques and technologies of justification of existing power-institutional configuration, basic forms and the parameters of political actors functioning; b) of legitimate regime - as a comprehensive, systematic phenomenon, reflecting the state and assessment of actual power-law relations, forming in the process of thinking activity of political actors and their interaction on the realization of the common good, the national interest, etc. "Legitimate" - is the estimated characteristic, applying either to any specific political actors and their actions (personified legitimacy), or existing institutions and public-authoritative activity (institutional, impersonal). The interconnection of the processes and modes of legitimizing and the regimes of the legitimate functioning of the government reflects regularities and contingencies in the evolution of the national political order.

5.2. Architectonics (multilevel structure) of legitimacy in the modern political and legal process involves several interconnected layers (levels): 1) the types of internal (motivational) and external (institutional) legitimacy; 2) the types of legitimate domination defining the dominant strategies strategies of substantiation of existing institutions and the ways of social processes managing; 3) the regimes of the legitimation; 4) the forms of substantiation of a state power as such, and its inherent institutional and legal structure. 


\section{References}

Baranov, P.P. and Gorshkolepov A.A (2002) Supreme Power as an Ideological Initial Element of a Statehood // Philosophy of Law. 2002. № 1. pp. 15 - 25.

Bachinin, V.A. (2005) Politics: Encyclopedic Dictionary. St. Petersburg. pp. 540.

Bourdieu, P. (1993) Sociology of Politics. M

Weber, M. Economy and Society. Part 1: The Economy. The Social Structure and the Authority. electronic resource: http://www.soc. pu.ru:8101/persons /golovin/__weber2.html

Volkov, V.V. (1998) "Following the Rules" as a Sociological Problem // Journal of Sociology.

Dibirov, A.N-Z. (2007) The Theory of Political Legitimacy: Lectures. M. pp. 272.

Isaev, I.A. (2003) Politica Hermetica: Hidden Aspects of Power. M. pp. 590.

Mannheim, K. (1994) The Diagnosis of our Time. M. pp. 670.

Filippov, A.F. (2002) Political Sociology. Fundamental Problems and the Basic Concepts // Politiya. Number 2.

Foucault, M. (1996) The Will to the Truth. On the Other Side of Knowledge, Authority and Sexuality. M.

Chirkin, V.E. (1995) The Legalization and Legitimization of State Authority// State and right. № 8. pp. 64-72

Alexey, I. Ovchinnikov, Alexey Y. Mamychev and Svetlana F. Litvinova (2015) Extra-Legal and Shadow Functioning of Public Authorities // Mediterranean Journal of Social Sciences. MCSER Publishing, Rome-Italy. Vol 6. No 3. pp. 387-394.

Andrey, Y. Mordovcev, Tatyana V. Mordovceva and Aleksey Y. Mamichev (2015) The Convergence of Law: The Diversity of Discourses // Mediterranean Journal of Social Sciences. MCSER Publishing, Rome-Italy. Vol 6. No 3. pp. 262-270.

Alexey, Y. Mamychev, Evgeniya Y. Kiyashko and Alla A. Timofeeva (2015) Conservative Political Transformation Projects of the Russian Government: The Main Discourses of Contemporaneity // Mediterranean Journal of Social Sciences. MCSER Publishing, RomeItaly. Vol 6. No 3. S. 2. pp. $389-396$.

Berger P.L. and Luckmann T. (1966) The Social Construction of Reality. A Treatise on sociology of Knowledge. pp. 249.

Chabot J.- L. (1991) Introduction a la politigue. pp. 240.

Clemens, E.S. and Cook J.M. (1999) Politics and institutionalism: Explaining durability and change // Annual review of sociology. Palo Alto, Calif. Vol. 25.

Easton, D. (1960) A Framework for Political Analysis. Englywood Cliff.

Hall, P.A. and Taylor R. (1996) Political Science and Three new institutionalism // Political studies. Vol. 44.

Quermonne, J.-L. (1986) Les regimes politigues occidentaux. P.

Lira, J. (1988) Legitimacy of democracy and the socioeconomic system // Comparing pluralist democraties: Strains on legitimacy. Boulder Westview.

Landort, P. and Goldring L. (2010) Political cultures and transitional social fields: Chileans, Colombians and Canadian activists in Toronto // Global Networks. - Hoboken, New Jersey: Blackwell Publishing Ltd, Global Networks. Vol. 10. No. 4

Lounsbury M. and Glynn M.A. (2001) Cultural entrepreneurship: Stories, legitimacy, and the acquisition of resources // Strategic management journal. - Hoboken, N.J. - Vol. 22.

March J.G. and Olsen J.P. (1984) The new institutionalism: Organizational factors in political life // American political science review. Wash., D.C. Vol. 78. No 3.

Poulantzas N. (1978) L'Etat, le pouvoir, le cocialisme. pp. 360. 